\title{
Experimental Tests on a Pre-Heated Combustion Chamber for Ultra Micro Gas Turbine Device: Air/Fuel Ratio Evaluation
}

\author{
Roberto Capata, Kliton Kylykbashi, Alfonso Calabria, Mario Di Veroli \\ Department of Mechanical and Aerospace Engineering, University of Roma "Sapienza”, Roma, Italy \\ Email: oberto.capata@uniroma1.it
}

How to cite this paper: Capata, R., Kylykbashi, K., Calabria, A. and Di Veroli, M. (2016) Experimental Tests on a Pre-Heated Combustion Chamber for Ultra Micro Gas Turbine Device: Air/Fuel Ratio Evaluation. Engineering, 8, 789-805.

http://dx.doi.org/10.4236/eng.2016.811071

Received: September 6, 2016

Accepted: November 14, 2016

Published: November 17, 2016

Copyright $\odot 2016$ by authors and Scientific Research Publishing Inc. This work is licensed under the Creative Commons Attribution International License (CC BY 4.0).

http://creativecommons.org/licenses/by/4.0/ (c) (i) Open Access

\begin{abstract}
Current portable power generators are mainly based on internal combustion engine since they present higher values of efficiency comparing to other engines; the main reason why internal combustion engine is not convenient for micro power generation $(5-30 \mathrm{~kW})$ is because of their heaviness. Micro and ultra micro gas turbine devices, based on a micro compressor and a micro turbine installed on the same shaft, are more suitable for this scope for several reasons. Micro turbine systems have many advantages over reciprocating engine generators, such as higher power density (with respect to size and weight), extremely low emissions and few, or just one, moving part. Those designed with foil bearings and air-cooling operate without oil, coolants or other hazardous materials. Micro turbines also have the advantage of having the majority of their waste heat contained in their relatively high temperature exhaust. Micro turbines offer several potential advantages compared to other technologies for small-scale power generation, including: a small number of moving parts, compact size, lightweight, greater efficiency, lower emissions, lower electricity costs, and opportunities to utilize waste fuels. The object of this study is the experimental tests on a stand-alone gas turbine device with a pre-heated combustion chamber (CC), to validate the fuel consumption reduction, compared to an actual and commercial device, used on air models.
\end{abstract}

\section{Keywords}

Experimental Tests, Combustion Chamber, Ultra Micro Gas Turbine, Fuel Consumption

\section{Introduction}

Current portable power generators are mainly based on internal combustion engine 
(ICE) since they present higher values of efficiency comparing to other engines; the main reason why ICE is not convenient for micro power generation $(5-30 \mathrm{~kW})$ is because of their heaviness. Micro and Ultra Micro Gas Turbine (UMGT) devices, based on a micro compressor and a micro turbine installed on the same shaft, are more suitable for this scope for several reasons. They present a higher power density, both in terms of $\mathrm{kW} / \mathrm{kg}$ and $\mathrm{kW} / \mathrm{m}^{3}$, lower emissions, less moving elements, multi-fuel capability (they operate almost equally well with kerosene, natural gases, propane). The main reason why UMGT is not currently realized is due to their low efficiency. In fact, while today large-scale commercial turbo-gas power plants reach the $40 \%$ mark, micro turbosets rarely exceed $15 \%$ [1]. Low efficiency on such an engine is related to the high velocity the fluid has inside the turbo machinery channels which lower the efficiency of the compressor and the turbine, the combustion process. The object of this study is the experimental tests on a stand-alone UMGT pre-heated combustion chamber (CC), to validate the fuel consumption reduction, compared to an actual UMGT, used on air models. The actual device is a single-stage radial compressor (C) and an axial turbine (T). The small dimensions of the turbo machinery lead to a very high rotational speed, which places severe demands on the bearings. Once known all operational data for the model, a thermodynamic analysis has been performed, by numerical simulation, to confirm and check the operational data and the simulation itself. Finally, a pre-heated CC (already realized, patented and tested) has been tested [2] [3], to evaluate the fuel consumption and to compare to the actual device.

\section{The UMGT Device}

The model previously tested [3] is a Jetcat ${ }^{\mathrm{Tm}} \mathrm{P} 200-\mathrm{SX}$ micro-turbine (Figure 1). All operational data has been measured [2] [3], in particular the fuel consumption. The results of the experimental tests are reported in the Table 1 . The used fuel is a $\mathrm{CH}_{4}$ methane. The devices is realized to burn typical kerosene liquid fuel, but the manufacturer suggests and indicates how to convert it for burning a gas fuel [4].

Table 1. Jet cat operational data [4].

\begin{tabular}{cc}
\hline Compressor inlet temperature $[\mathrm{K}]$ & $284-298$ \\
Compressor outlet temperature $[\mathrm{K}]$ & $309-405$ \\
Compressor inlet pressure $[\mathrm{bar}]$ & 1.013 \\
Compressor pressure ratio $(\beta)$ & 2.2 \\
Air mass flow rate $[\mathrm{kg} / \mathrm{s}]$ & 0.30 \\
Fuel mass flow rate & \\
Kerosene $[1 / \mathrm{min}]$ & $0.123-0.796$ \\
Methane $[1 / \mathrm{min}]$ & $3.3-10.6$ \\
Turbine inlet temperature $[\mathrm{K}]$ & $780-1078$ \\
Turbine outlet temperature $[\mathrm{K}]$ & $770-890$ \\
Rotational speed $\mathrm{n}[\mathrm{rpm}]$ & $30000-120000$ \\
\hline
\end{tabular}




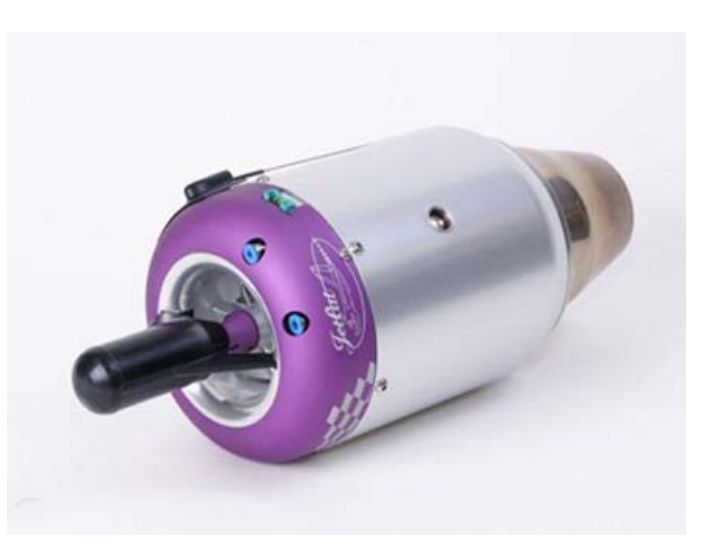

Figure 1. Jetcat device.

\section{The UDR1 UMGT Proposal}

In the philosophy of fuel consumption reduction, the possibility of replacing the combustion chamber with an improved chamber has been considered. In previous articles have been experimentally assessed the pressure drops, introduced by the new device (see Figure 2), and the map of thermal field [3] [5]. Below is a briefing description of the combustion chamber and the heater, for completeness.

\subsection{Air Pre-Heater}

The air pre-heater and the combustion chamber have been designed, developed, patented and manufactured at the Mechanical and Aerospace Engineering Department of University La Sapienza-Roma. Their most relevant feature is the particular single-body design: the air pre-heater spirals along the outer face of the cylindrical combustion chamber. As matter of fact, the pre-heater is very efficient, lighter, and performs as a thermal insulator for the combustor.

\subsection{Combustion Chamber}

It is a patented device. A first order thermo-fluid dynamic simulation was performed to assess the attainment of a satisfactory thermal field and the completeness of combustion (see Table 2). A series of specifically dedicated tests [2] [3] [6] provided the temperature map of the $\mathrm{CC}$ for a more exact analysis of the thermal flows and for experimentally validating the CFD results obtained in a previous paper of the same research group at University [7]. The spark plug, needed to activate the ignition of the air-fuel mixture, is located on the top. In Figure 2 the compressor air inlet is indicated by the (A): the air flows through the spiraling duct and is pre-heated, and enters the combustion chamber from the upper side of the combustion chamber. The combustion air is injected with an intense swirling motion, enhancing mixing with the fuel. The fuel is injected through a second duct ( $\mathrm{B}$ in Figure 2). The products of combustion exit the inner cylinder from a port located on the opposite (bottom) side of the chamber. The inner diameter of the assembled combustion chamber is $2.2 \mathrm{~cm}$, its outer diameter 4.2 $\mathrm{cm}$ and the overall height $13.0 \mathrm{~cm}$. In Table 3 all technical data of the proposed CC. 

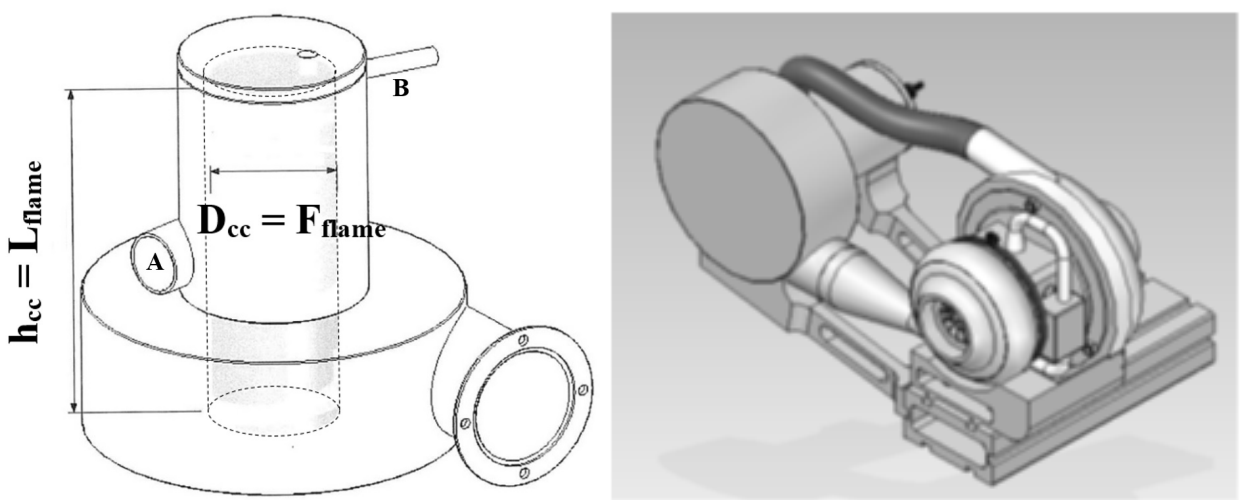

Figure 2. The assembled combustion chamber and possible modification of Jetcat device.

Table 2. Technical data.

$\begin{array}{cc}m_{\text {air }}[\mathrm{kg} / \mathrm{s}] & 0.5 \\ \text { Air inlet pressure }[\mathrm{Pa}] & 175000 \\ \text { Air inlet temp. }[\mathrm{K}] & 374 \\ m_{\text {fuel }}[\mathrm{kg} / \mathrm{s}] & 0.32 \\ \text { Fuel inlet pressure }[\mathrm{Pa}] & 200000 \\ \text { Fuel inlet temp. }[\mathrm{K}] & 300 \\ \Delta p_{\mathrm{CC}} & 8000 \\ \text { Exhaust outlet pressure }[\mathrm{Pa}] & 167000 \\ \text { Exhaust outlet temp. }[\mathrm{K}] & 1383 \\ \eta_{\mathrm{CC}} & 0.7 \mathrm{mcc} \\ \text { LHV [J/kg] } & 50000000\end{array}$

Table 3. CC operating parameters.

\begin{tabular}{|c|c|c|c|}
\hline$V_{\text {air }}[\mathrm{m} / \mathrm{s}]$ & 40 & $\Phi_{\text {flame }}[\mathrm{m}]$ & 0.1278 \\
\hline Residential time $t_{r}[\mathrm{~s}]$ & 0.012 & $L[\mathrm{~m}]$ & 0.2526 \\
\hline & \multicolumn{3}{|c|}{ External surface inlet (Section 1) Chamber inlet (Section 2) Chamber outlet (Section 3) } \\
\hline$p[\mathrm{~Pa}]$ & 175000 & 175000 & 167000 \\
\hline$T[\mathrm{~K}]$ & 374 & 504 & 1283 \\
\hline$R[\mathrm{~J} / \mathrm{kg} \mathrm{K}]$ & 287 & 287 & 300 \\
\hline$\rho\left[\mathrm{kg} / \mathrm{m}^{3}\right]$ & 1.63 & 1.22 & 0.43 \\
\hline$Q\left[\mathrm{~m}^{3} / \mathrm{s}\right]$ & 0.031 & 0.041 & 0.115 \\
\hline$A\left[\mathrm{~m}^{2}\right]$ & 0.00077 & 0.001003 & 0.0029 \\
\hline$D[\mathrm{~m}]$ & 0.0312 & 0.0356 & 0.0606 \\
\hline Material & Inconel 617 & Inconel 617 & Inconel 617 \\
\hline
\end{tabular}




\section{Description of the TEST BENCH}

The test bench is composed by 3 different circuits:

1) Air supply line;

2) Fuel supply line;

3) Exhausts line.

Here follow the main characteristics for all components, instruments and line are reported and described.

\subsection{The Fuel Supply Line}

Two different circuits have been considered. The gas circuit and the air supply circuit. The circuit are constituted by tubes and hoses. The tubes are 1/2 inches Whitworth thread hydraulic type. The hoses are gas type resistant: AD 8 IEMMEQ UNI CIG $7140 / 93$. The rubber gas hose, from the cylinder gas, is connected to the gas circuit, at the yellow valve (Figure 3(a)) with a metal clamp. The close position is shown in figure (the knob is perpendicular to the tube). The yellow valve is a security valve (on/off), and it must not be used as a flow regulation valve. The second valve (with the red knob) is used to regulate the gas flow. The circuit is connected to the municipal $\mathrm{CH}_{4}$ supply line.

This valve must be handled with care, because it is a micrometric type valve. Next, along the circuit, there are two types of flow meter. The first one is shown in the picture $3 c$. The second one is presented in figure 4 a.Next the flow meter, is installed an automatic normally closed solenoid valve for gas (Figure $3(\mathrm{~b})$ ). This type of valve open when the coil is powered and close when there is no tension. It is controlled by a thermostat (with a $450^{\circ} \mathrm{C}$ as temperature security limit). From the normally closed valve, the gas flows into a $9 \mathrm{~mm}$ copper tube that finally comes into the combustion chamber as can be seen in the picture $4 \mathrm{c}$.

\subsection{The Air Supply Line}

The air circuit is made by hydraulic tubes and copper tube. The hydraulic tubes are the same used for the gas circuit also for the copper one. The air circuit is powered by a

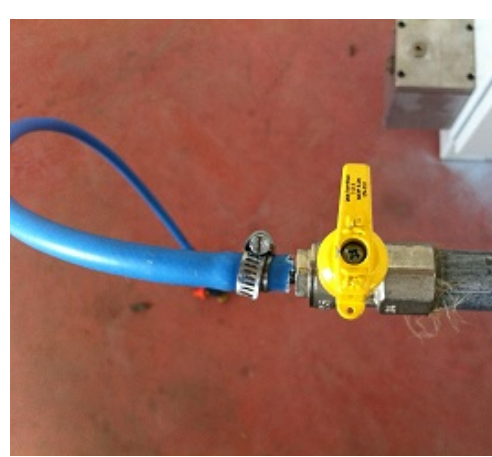

(a)

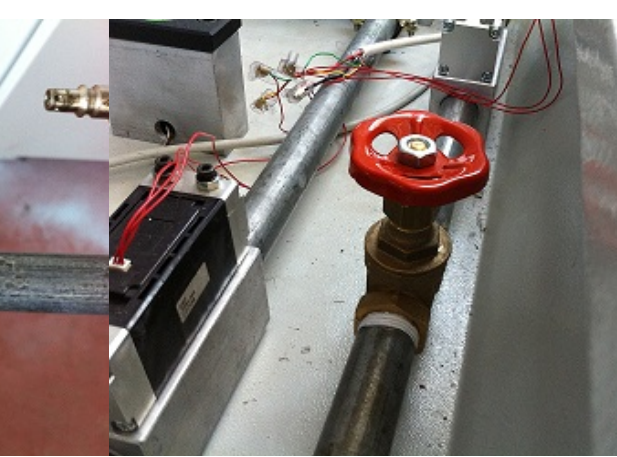

(b)

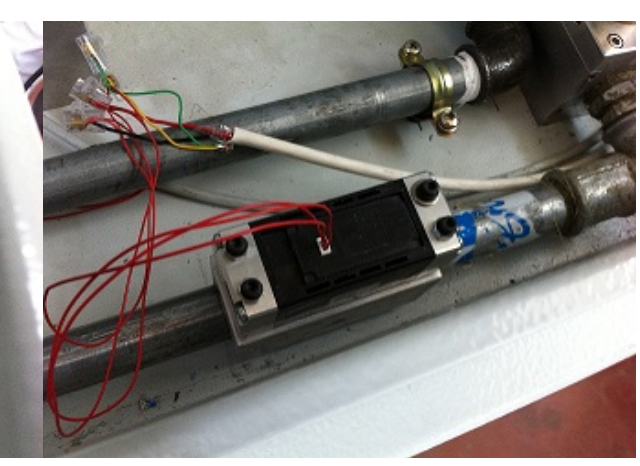

(c)

Figure 3. (a) Supply valve; (b) regulation valve; (c) flow meter. 
screw compressor with a capacity of 207 liters at 9 bar. The connection between the compressor and the air circuit test bench is possible by the blue hose that can be seen in the picture above. It must be fit on the air circuit with a metal clamp securely tightened because the high air pressure inside the hose can be very dangerous for the operators, in case of accidental hose separation from the hydraulic tube. Analogously the gas circuit, there is a red knob valve, in order to regulate the air flow, and the same flow meter shown in Figure 4. The on/off valve is located next the flow meter. By a copper tube, the air can flow into the combustion chamber, as can be seen in the picture below (Figure 5).

\subsection{The Measuring Instruments}

The instruments used are described below.

\subsubsection{He Gas Mass Flow Meter MCR Series}

MCR series.

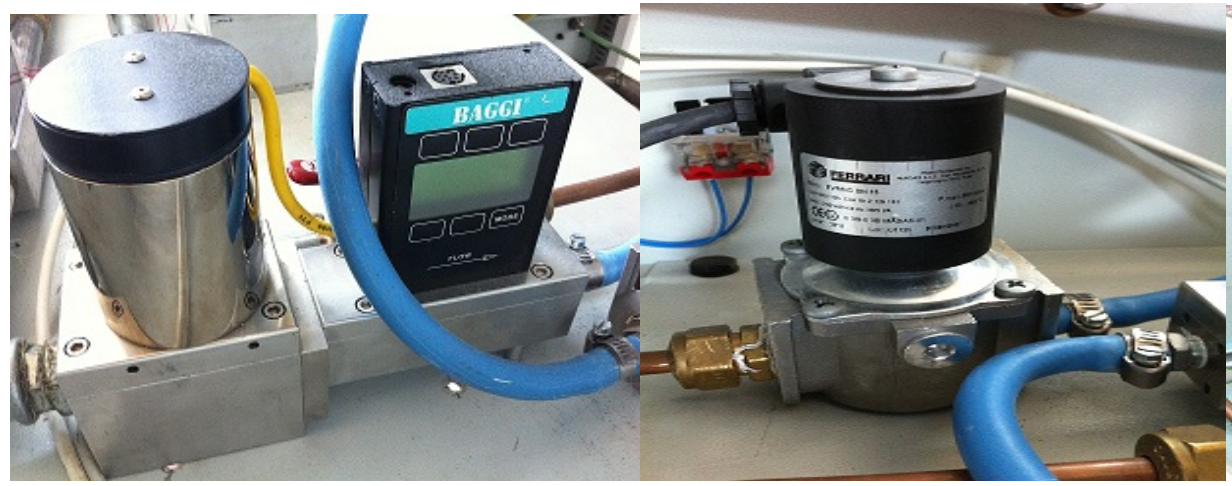

(a)

(b)

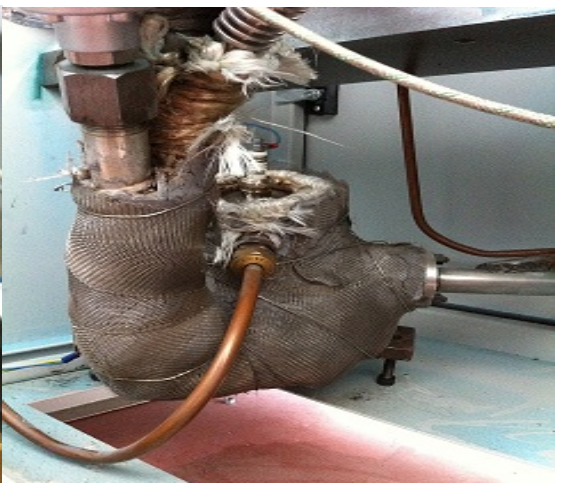

(c)

Figure 4. (a) Flow-meter; (b) solenoid valve; (c) the CC connection circuit and location in the test bench.

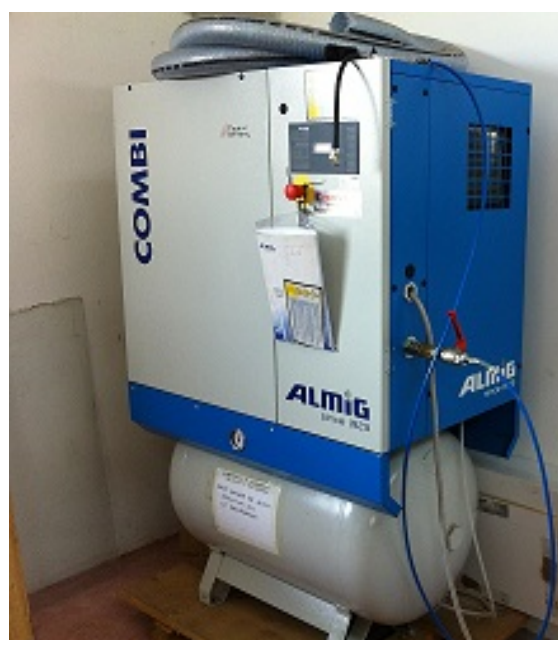

(a)

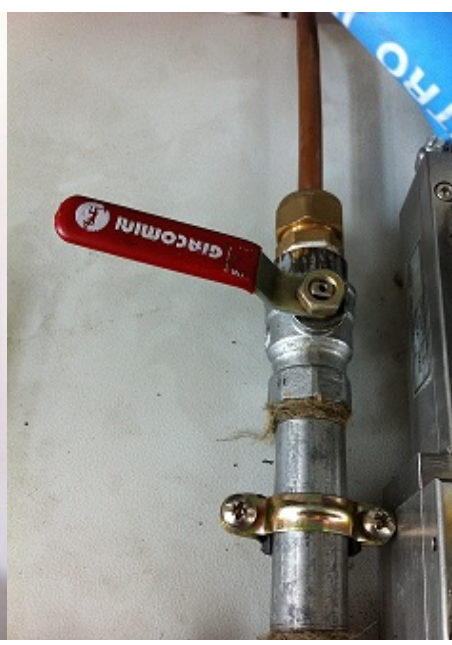

(b)

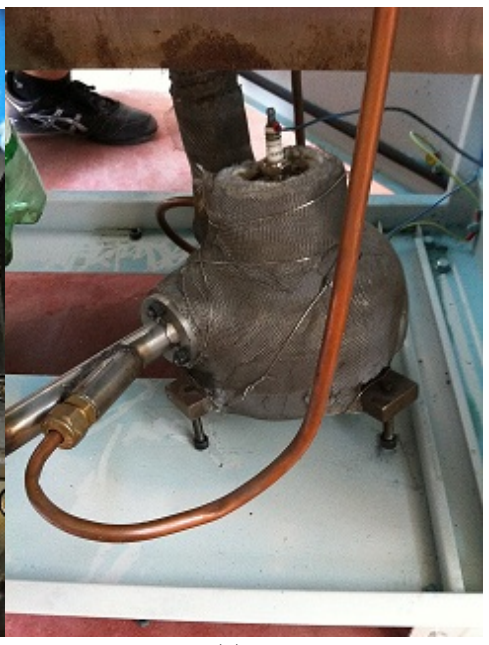

(c)

Figure 5. (a) Air supply; (b) the on-off manual valve; (c) copper air pipe into CC. 
MCR-100 SLPM-D-G model.

Serial number 39209.

Calibration date: $02 / 25 / 2016$ by Jaw.

When the main mode in selected, some parameters are displayed. The device is shown in Figure 6.

- Gas absolute pressure: this sensor references hard vacuum and reads incoming pressure both above and below local atmospheric pressure. This parameter is moved to the primary display by pushing the button above $\mathrm{Psi}_{\mathrm{A}}$. The engineering unit associated with absolute pressure is pounds per square inch absoluter $\left(\mathrm{Psi}_{\mathrm{A}}\right)$. This can be converted to gage pressure $\left(\mathrm{Psi}_{\mathrm{G}}\right)$ by subtracting local atmospheric pressure from the absolute pressure reading:

$\mathrm{Psi}_{\mathrm{G}}=\mathrm{Psi}_{\mathrm{A}}-$ local atmospheric pressure.

- Gas temperature: MCR series flow controllers measures the incoming temperature of the gas flow. The temperature is displayed in degrees Celsius $\left({ }^{\circ} \mathrm{C}\right)$ this parameter is moved to the primary display by pushing the button above ${ }^{\circ} \mathrm{C}$.

- Volumetric flow rate: this parameter is located in the lower left of the display. It is moved to the primary display by pushing the button below CCM.

- Mass flow rate: the mass flow rate is the volumetric flow rate corrected to a standard temperature and pressure (typically $14,696 \mathrm{Psi}_{\mathrm{A}}$ and $25^{\circ} \mathrm{C}$ ) this parameter is located in the lower middle of the display.

To get an accurate volumetric or mass flow rate, the flag "gas measure" must be selected. The gas selected menu is accessed by the relative button on the selected menu display. The instrument let to choose the gas from a standard gas select list. This is critical step because the flow meter needs to know the gas density in order to calculate the mass flow. The density of the gas changes with temperature and pressure. Using the ideal gas laws, the effect of the temperature on density is: $\rho_{\mathrm{a}} / \rho_{\mathrm{s}}=T_{s} / T_{\mathrm{a}}(1)$, where $\rho_{\mathrm{a}}$ is the density at flow condition, $T_{a}$ absolute Kelvin temperature at flow condition, $\rho_{\mathrm{s}}$ density at standard condition, $T_{s}$ absolute Kelvin temperature at standard condition. The density change with pressure can be described with the same law. Therefore in order to

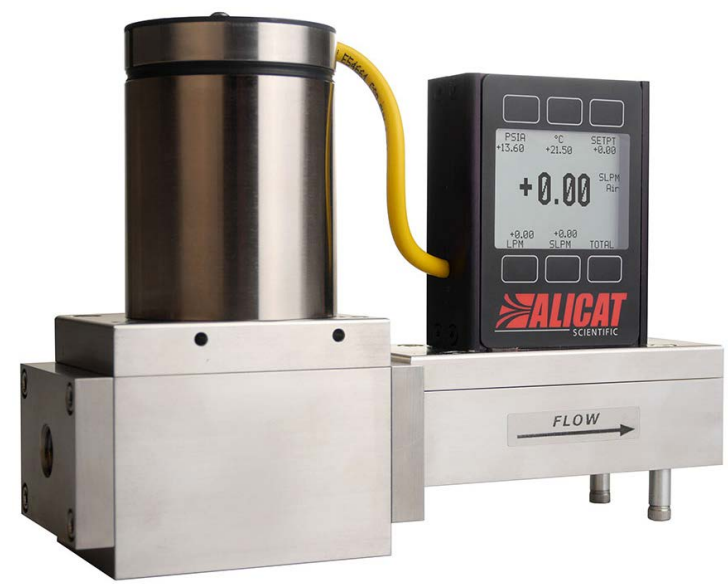

Figure 6. The flow meter assembling. 
determine mass flow rate, two correction factor must be applied to volumetric rate: temperature effect on density and pressure effect on density. But some gases, as for example propane and butane, cannot be described by an ideal law. For this reason the compressibility factor $\mathrm{Z}$ must be considered. So the non-ideal gas law is formulated in this way: $\mathrm{P} V=\mathrm{nZRT}$ (2). As the compressibility factor goes down $(\mathrm{Z}=1$ is the ideal gas condition), the gas takes up less volume than what one would expect from the ideal gas calculation. The flow corrections are normally made to $25^{\circ} \mathrm{C}$ and $14,696 \mathrm{Psi}_{\mathrm{A}}$ and the compressibility factor of the gas under those conditions. This allows the user to multiply the mass flow rate by the density of the real gas at those standard conditions to get the mass flow rate in grams per minute. Although the correct unit for mass are expressed in grams, kilograms, etc. it has become standard that mass flow rate is specified in standard liters/minute (SLPM). This means that mass flow rate is calculated by normalizing the volumetric flow rate to some standard temperature and pressure (STP). By knowing the density at STP, it is possible to determine the mass flow rate in grams per minute, kilograms per hour, etc. STP is usually specified at sea level conditions, for example $25^{\circ} \mathrm{C}$ and $14,696 \mathrm{Psi}_{\mathrm{A}}(101.32 \mathrm{kPa})$.

\subsubsection{The Air Velocity Sensor}

It is an dedicated device type OMRON D6F-10A5-000 22ZOR and the instrument operating characteristics are reported in table. The air flow meter is $5 \mathrm{~V}$ powered, but in our experience, this value needs to be reduced in order to get enough sensibility of results. So, two electrical resistances series mounted, one about $100 \mathrm{k} \Omega$ and the other one about $400 \mathrm{k} \Omega$, are used in the power supply circuit. In this way, the supply voltage goes down to $1 \mathrm{~V}$. Although the electrical modification, the flow meters measuring range is still limited than the actual flow values. For this reason, the flow meter is used as the principal measuring instrument to get an accurate flow value. The operational device characteristics are reported in Table 4.

\subsubsection{The Temperature Controller}

It is a digital controller device. It has been designed for temperature control in any application involving heating or cooling processes (Figure 7). Characteristic:

1) Universal input for TC, $2 / 3$ wire RTD, PTC, NTC, and linear thermocouples, supplied with current and voltage with accuracy better than $0.2 \%$.

2) Standard output: one relay and the other relay/logic/triac. Functions heat/cool, self-tuning, auto-tuning, soft start. Alarm for interrupted load or short circuited probe. Service serial line for PC configuration.

\subsubsection{Safety Valve}

Madas EVP is an automatic normally closed valve (Figure 7) for gas EN 161 EC

Table 4. Device characteristics.

\begin{tabular}{ccccccc}
\hline Flow rate (liter/min) & 0 & 2 & 4 & 6 & 8 & 10 \\
Output voltage & 1 & 1.75 & 2.6 & 3.45 & 4.25 & 5 \\
\hline
\end{tabular}




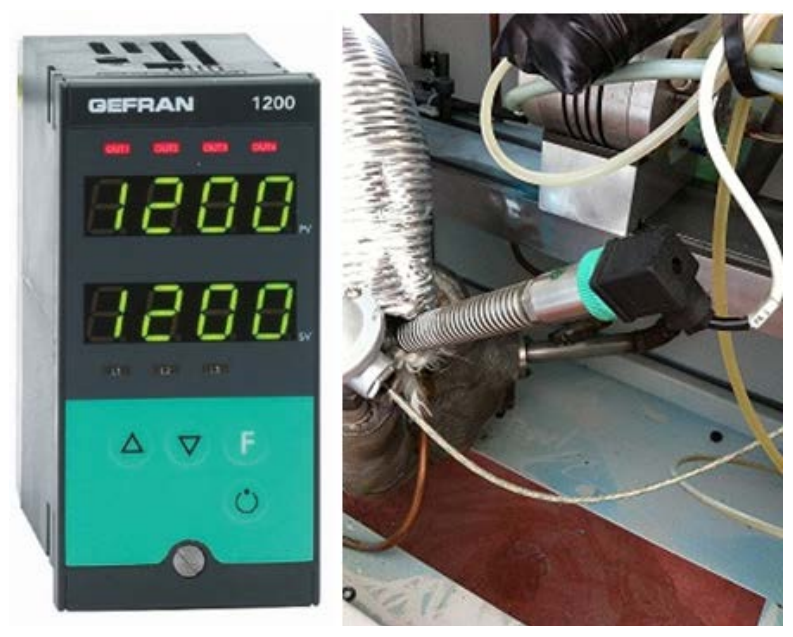

Figure 7. Controller.

approved, in conformity with Gas Directive 2009/142/EEC. It is a normally closed valve that open when the coil is powered and it is closed when there is no tension. In fact, when the valve is powered by tension, a magnetic field forced up the piston and the spring get compressed. When the tension is released, the spring force allows the piston to go down and close the gas passage. The solenoid valve is conformity with the Directive 94/9/CE (said Directive ATEX 100 a) as devices of group II, category 3G and as device of group II, category 3D; for this reason it is suitable to be installed in the zones 2 and 22 as classified in the attachment I to the Directive 99/92/EC. Device characteristics are listed in Table 5.

\section{Test Measure Protocol}

The experimental campaign was carried out, according to the following procedures:

\subsection{Definition of the Acquisition Time}

This parameter depends on the measurable whose value is sought after. During the tests 3 different operational modes occur:

- start-up;

- operational transient;

- Steady conditions.

All the tests are carried out in steady conditions, but the transient has been monitored too.

\subsection{GUM Experimental Results Post-Treatment}

The Guide to the Expression of Uncertainty in Measurement is published by the International Organization for Standardization (ISO) in the names of seven international scientific organizations [8]. It is based on specific recommendations of the International Committee for Weights and Measures (CIPM). The ISO Guide has been adopted by most of the national metrology institutes (NMIs) and regional metrology organizations 
Table 5. Device characteristics.

\begin{tabular}{|c|c|}
\hline Use & Not aggressive gases (dry gases) \\
\hline Environment temperature & $-20^{\circ} \mathrm{C}-60^{\circ} \mathrm{C}$ \\
\hline Max superficial temperature & $85^{\circ} \mathrm{C}$ \\
\hline Power supply voltage & $12 \mathrm{~V} / 50 \mathrm{~Hz}-24 \mathrm{~V} / 50 \mathrm{~Hz}-110 \mathrm{~V}-230 \mathrm{~V} / 50-60 \mathrm{~Hz}$ \\
\hline Power supply voltage tolerance & $-15 \% \ldots+10 \%$ \\
\hline Electric connection & Cable gland PG 13,5 \\
\hline Cycles/hour & Max 1050 \\
\hline Power absorption & See specifications \\
\hline Max working pressure & 200 or 360 mbar (see product label) \\
\hline Closing time & $<1 \mathrm{sec}$ \\
\hline Degree of protection & IP65 \\
\hline Class & A \\
\hline Group & 2 \\
\hline Threaded connection RC & (DN 15 - DN 50) according to EN 10226 \\
\hline Threaded connection NPT & On request \\
\hline
\end{tabular}

(RMOs) in the world [9]. The objective of a measurement is to determine the value of the measurable that is, the value of the particular quantity to be measured. A measurement therefore begins with an appropriate specification of the measure and, the method of measurement and the measurement procedure. In general, the result of a measurement is only an approximation or estimate of the value of the measurable and thus is complete only when accompanied by a statement of the uncertainty of the estimate. The uncertainty of the result of a measurement reflects the lack of exact knowledge of the value of the measurable [10]. The ISO Guide recognizes that some components of uncertainty may be evaluated from statistical methods and some must be determined by other means, meaning scientific judgment. The components of uncertainty evaluated from statistical analysis of current measurements are referred to as Type A, and the components of uncertainty determined by scientific judgment based on other measurements or published data are referred to as Type B [9].

\subsection{1. $T_{m}$ Uncertainty}

To describe this procedure, the temperature measurements treatment is explained. All measurements are treated as well.

$$
\Delta T_{i}=T_{i}-T_{i n}
$$

where $T_{i}$ is the $i^{\text {th }}$ temperature measurement and $T_{i n}$ is the water inlet temperature.

Then:

$$
\Delta T_{m}=\frac{\sum_{i} \Delta T_{i}}{N}
$$


with $N$ number of available data. The reports provided by the GUM, assuming a Gaussian distribution of the distribution of temperature measurements, the expanded uncertainty on the $\Delta T_{m}$ assumes equal to [8]:

$$
U(x)=k u_{C}(x)=k \frac{\sigma_{x}}{\sqrt{N}}
$$

where: $U(x)$ is the expanded uncertainty, $k$ is the coverage factor, $u(x)$ is the combined standard uncertainty and $\sigma_{x}$ is the standard deviation.

The standard deviation is given by:

$$
\sigma_{x}=\sqrt{\frac{\sum_{i=1}^{N}\left(x_{i}-\bar{x}\right)^{2}}{N-1}}
$$

where $x_{i}$ is the generic measurement and $x_{i s}$ the median value of the measured values. At last, setting $k=3$. This condition would have $99 \%$ probability that the calculated $\Delta T_{m}$ is actually in the identified band, if the distribution of the measurements actually has a Gaussian shape [11].

\subsection{Elapsed Time}

The tests were performed in several sessions (15), with actual preparation/acquisition time for each session between 2 - 3 hours, and sufficiently long intervals between two test sessions for the system to return to its "zero" conditions.

\section{Test Procedure}

Here follow the sequence and the necessary steps to carry out the tests.

1) Set the red lever in close position (Figure 8);

2) Connect to the grid. Set compressor switch to " 1 ";

3) Check the connection pipe;

4) Open the air supply line (red lever);

5) Initialize the ventilation system.

After this first phase, once all steps are completed and all safety device are checked, the instruments connection must be considered and the values must be set.

1) Initialize the flow meter.
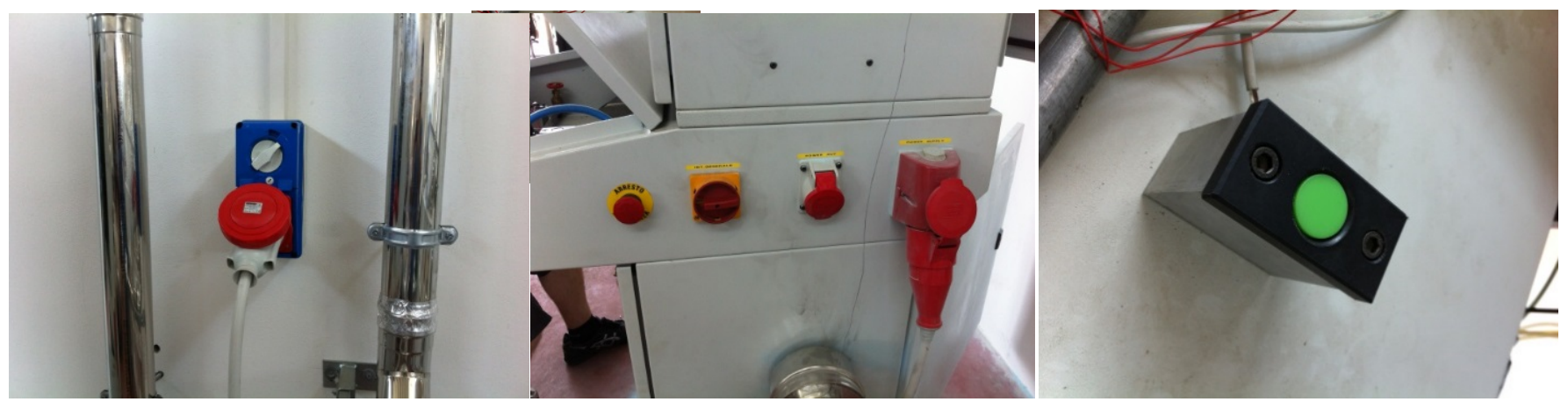

Figure 8. Compressor air supply and test bench switches Ignition button. 
2) Check the safety solenoid valve. If the test bench and the instrument are not powered the solenoid valves are normally closed.

3) Set yellow valve (fuel supply) in close position.

4) Open the compressor valve and the air red valve on the test bench, the air knob has to be settled at the minimum possible flow rate. It is about $1 / 8$ of turn.

5) Open the yellow gas valve, and adjust the knob until the value of $4 \mathrm{lit} / \mathrm{min}$ is reached (digital reading).

The further step are needed not to affect the measurement. The chamber has to be cleaned. So, the procedure is the following one:

1) Close the fuel valve.

2) Run the compressor to clean the chamber.

3) Check the exhaust line.

Once the chamber is cleaned, the actual test can be initiated. As well the steps are:

1) Press the green button (ignition button) and open the gas valve again.

2) After few seconds (2 - 3) close the yellow valve and wait for the gas ignition (the ignition occurs when the mixture becomes stoichiometric and create a flame front, which is powered by the gas in the chamber. In this phase is mandatory to maintain the inlet flow constant to stabilize the combustion).

3) Finally, connect the exhaust pipe line and the blower. The all tests were conducted within the Department laboratory. The outside chamber temperature test, during the trials, has varied between $16^{\circ} \mathrm{C}-18^{\circ} \mathrm{C}$ and pressure among 1.017 and 0.9987 bar. Then it was deemed reasonable to consider irrelevant the external conditions of testing and that measurements are not affected by their variation.

\section{Tests Results}

Once the combustion is ignited, the combustion parameters have been measured. The first obtained result is the combustion "stable point". This point is characterized by the gas flow rate of 2, $8 \mathrm{lit} / \mathrm{min}$. The flame is stable and consequently the combustion is maintained. The operational mode has been maintained for several minutes $(5 \mathrm{mi}$ nutes), to confirm the "stable conditions". This operation has been performed for each test, validating the experimental procedure. Another important result is the minimum value of the gas mass flow rate, to ignite the air-fuel mixture. This minimum value is about 1.2 lit/min. The burning starts, but fails to remain stable. The conditions are such as to cause continued shutdowns and firings, highlighted by the numerous and continuous bangs. At the same time, this phenomenon is highlighted by very large variations in temperature, detected by sensors devices. Fast elevations and sudden lowering are measured. As well as the rotational speed. Other typical point to spot is the auto shutoff, due to an excessive fuel flow. This point was found and the measured characteristic value is $9 \mathrm{lit} / \mathrm{min}$. When it reaches this value, the combustion shuts down, and the temperature and speed sensors confirm the occurred shutdown, with a quick lowering of system temperature and speed. Moreover, the lack of "subjective" combustion "noise" leads to consider that the flame shutdown has taken place. Finally, the stoichi- 
ometric combustion values. It was set by four different procedure, listed below. First, the system was numerically simulated, using some commercial and users developed software (Aspen, GateCycle, Camel). In all cases, the system simulations, introducing as input data the values defined by Jetcat [4], provided an alpha value between 15 and 16, corresponding to a flame temperature of about $1600^{\circ} \mathrm{C}$. The derived fuel flowrate value is $3.5 \mathrm{lit} / \mathrm{min}$. The second check was a visual check. During the tests, the combustion chamber was separated from the turbine, and it was possible to verify, visually, the progress of combustion. It was seen that combustion was complete. In fact, the flame had the characteristic and typical blue color, no yellow areas. This means that combustion is burning all the fuel. The measured flame temperature is about $1590^{\circ} \mathrm{C}$ (very close to the standard value for methane). In addition, the derived fuel flowrate value is about $3.5 \mathrm{lit} / \mathrm{min}$. Last check is related the noise. Some authors [11]-[15] have been correlated the noise high frequency to the complete combustion, at stoichiometric conditions. Also in this case, the maximum level is achieved within the range of $1580^{\circ} \mathrm{C}$ $1600^{\circ} \mathrm{C}$. All results are briefly reported in Table 6 and in the following graphs (Figures 9-13).

It is important to notice that, during the tests, the considered air density was equal to $\rho_{\mathrm{a}}=1.16 \mathrm{~kg} / \mathrm{m}^{3}$, while the gas density is $\rho_{\mathrm{g}}=2 \mathrm{~kg} / \mathrm{m}^{3}$.

\section{Tests Results}

The tests have provided very interesting data. The first obvious result was that, under all operating conditions, the new combustion chamber allowed about $15 \%$ of fuel saving (referring to the manufacturer's nameplate data). The value obtained is $3.5 \mathrm{l} / \mathrm{min}$ and $94.7 \mathrm{l} / \mathrm{min}$ for gas and air respectively.

Table 6. Experimental tests summarized values.

\begin{tabular}{|c|c|c|c|c|}
\hline $\begin{array}{l}\text { Volumetric gas } \\
\text { flowrate [lit/min] }\end{array}$ & $\begin{array}{l}\text { Volumetric gas } \\
\text { flowrate }\left[\mathrm{m}^{3} / \mathrm{min}\right]\end{array}$ & $\begin{array}{l}\text { mass gas } \\
\text { flowrate }[\mathrm{kg} / \mathrm{min}]\end{array}$ & $\begin{array}{l}\text { Volumetric percentage } \\
\text { gas flowrate }[\%]\end{array}$ & $\begin{array}{c}\text { (alpha) } \\
\text { (calculated) }\end{array}$ \\
\hline 1.2 & 0.0012 & 0.0024 & 0.013 & 45.79 \\
\hline 2.8 & 0.0028 & 0.0056 & 0.030 & 19.63 \\
\hline 3.5 & 0.0035 & 0.0070 & 0.037 & 15.70 \\
\hline 4.0 & 0.0040 & 0.0080 & 0.042 & 13.74 \\
\hline 9.0 & 0.0090 & 0.0180 & 0.095 & 6.11 \\
\hline \multicolumn{5}{|c|}{ Operational conditions } \\
\hline \multicolumn{3}{|c|}{ Combustion ignition } & $1.21 / \mathrm{min}$ & \\
\hline \multicolumn{3}{|c|}{ Stabilized combustion } & $2.8 \mathrm{l} / \mathrm{min}$ & \\
\hline \multicolumn{3}{|c|}{ Stoichiometric combustion } & $3.5 \mathrm{l} / \mathrm{min}$ & \\
\hline \multicolumn{3}{|c|}{ Operational (60000 - 90000 rpm) } & $4.0 \mathrm{l} / \mathrm{min}$ & \\
\hline \multicolumn{3}{|c|}{ Shutdown } & $9.0 \mathrm{l} / \mathrm{min}$ & \\
\hline
\end{tabular}




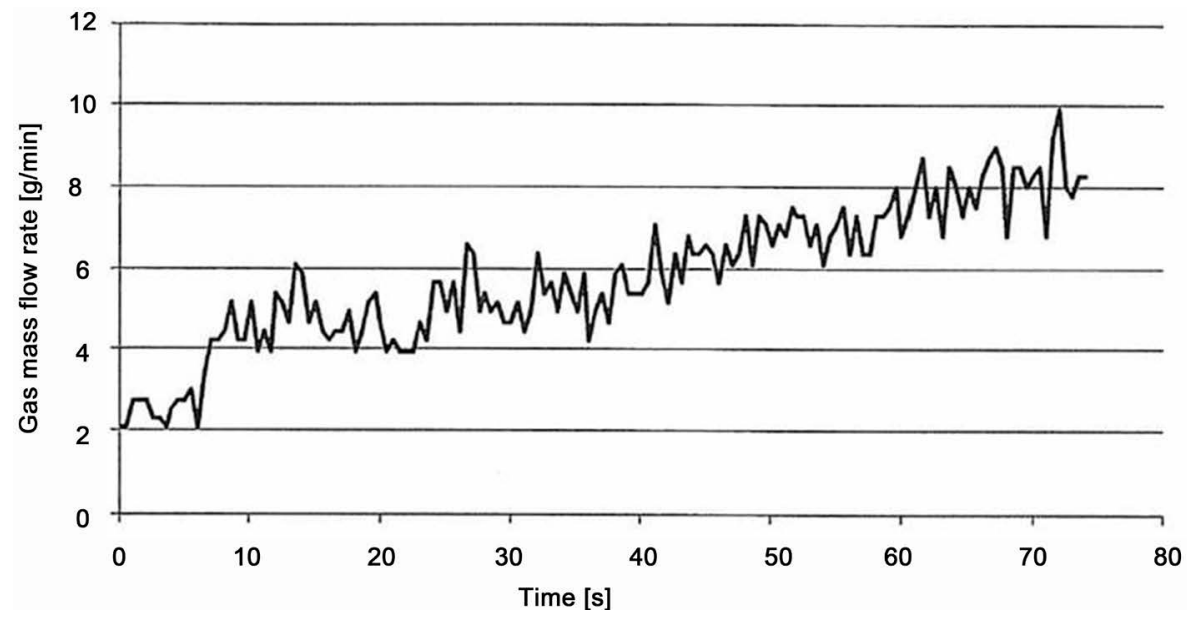

Figure 9. Fuel mass flow rate during start-up and running conditions.

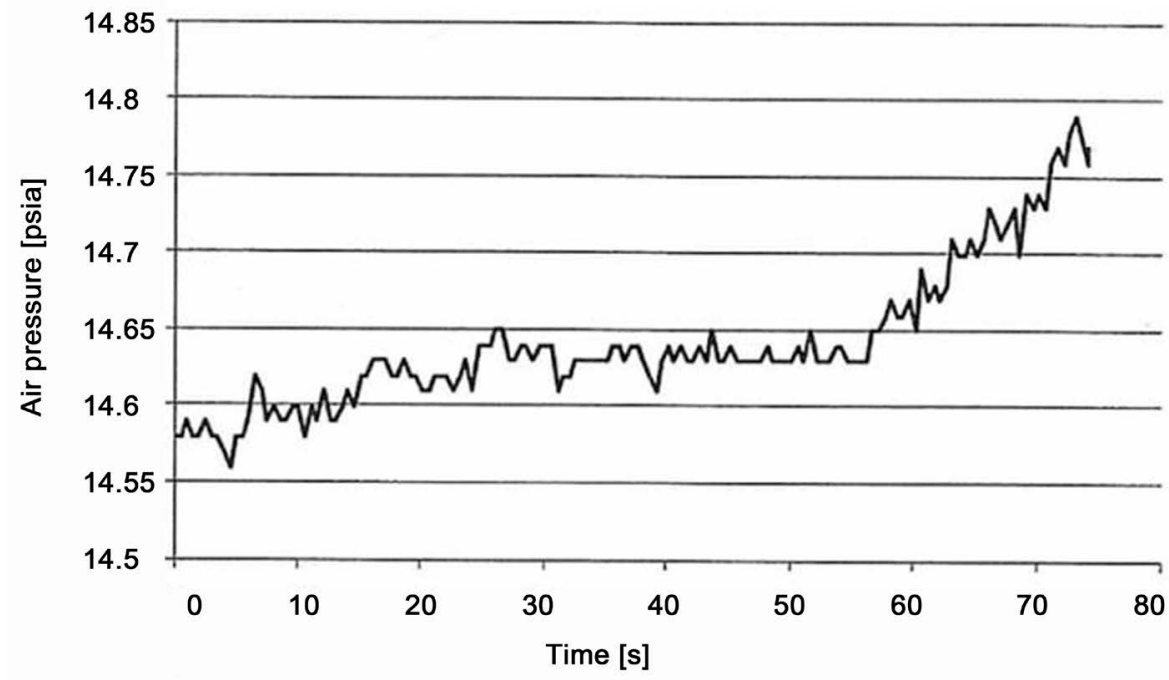

Figure 10. Air pressure during the tests.

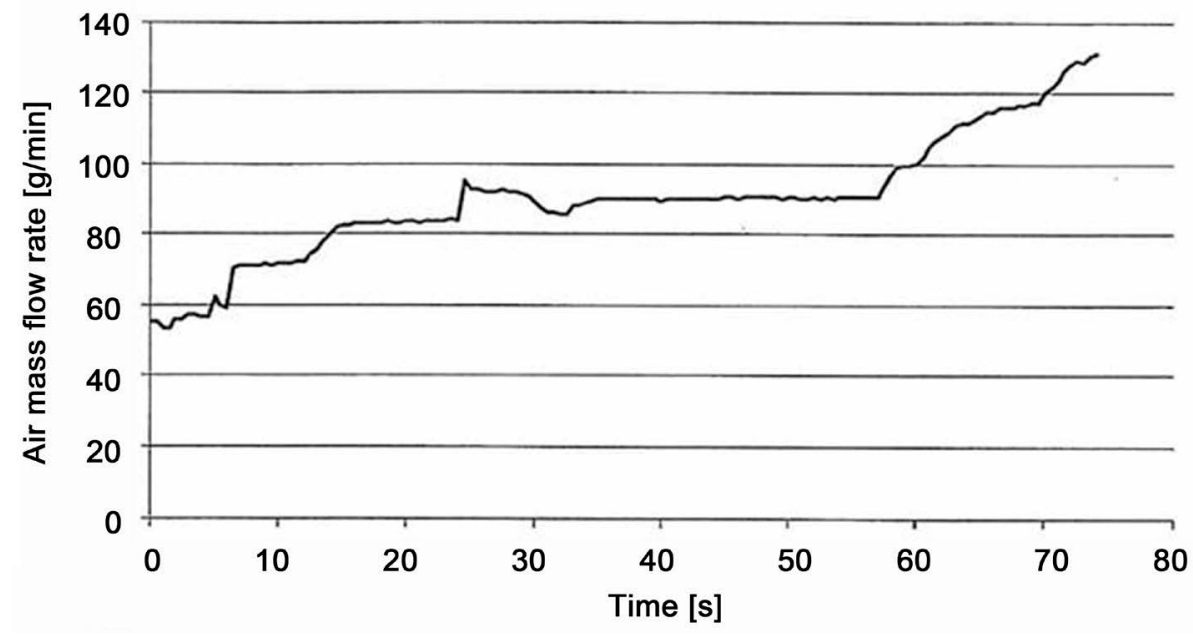

Figure 11. Air mass flow rate during start-up and running conditions. 


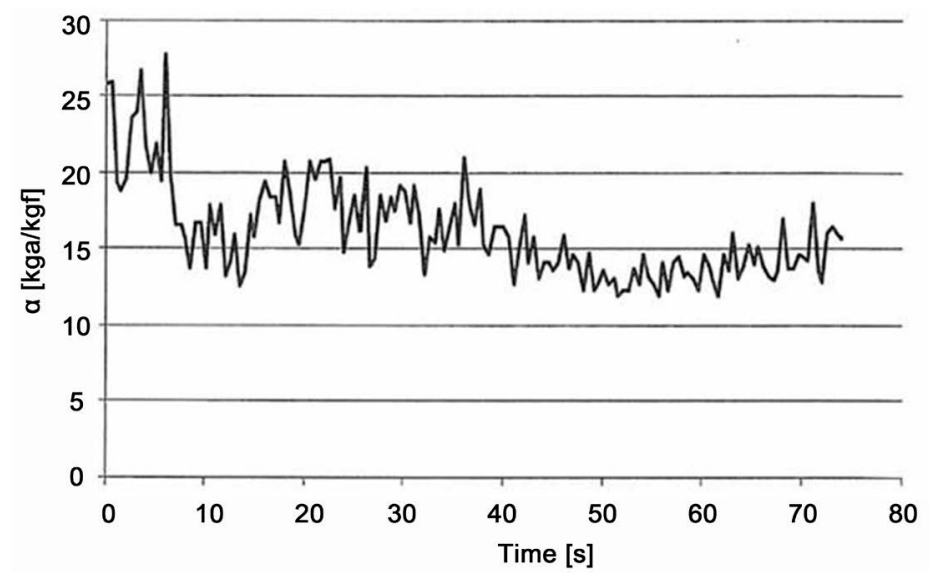

Figure 12. Mixture ratio $\alpha$ during tests.

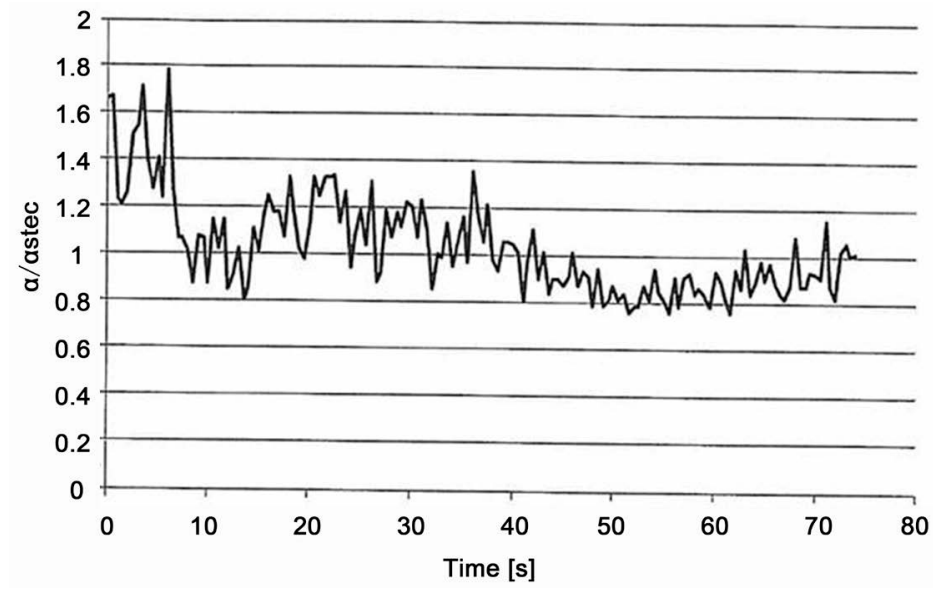

Figure 13. $\alpha / \alpha_{\mathrm{st}}$ variation during tests.

In addition, the various phases of the combustion process have been identified, establishing all operational points and determining the fuel and airflow rates required to maintain combustion. This, together with the previously tested and measured thermal field, led to the completion of the experimental analysis of the new combustion chamber (patented by our department).

It was, therefore, possible to experimentally identify the stoichiometric value, very close to theoretical one. This aspect can be considered a positive characteristic, for a possible use of the new combustion chamber in the new UMGT configuration.

The future plans are to optimize the chamber shape and materials, to make it lighter and propose it as a possible new UMGT combustion chamber for various applications.

\section{References}

[1] Capata, R. (2012) Ultra Micro Gas Turbine. Chapter of the Book "Efficiency, Performance and Robustness of Gas Turbines". InTech Publisher, 246 p.

[2] Capata, R., et al. (2013) Testing of the Ultra-Micro Gas Turbine Devices (1 - $10 \mathrm{~kW})$ for Portable Power Generation at University of Roma 1: First Tests Results. Engineering, 5, 
481-489. http://dx.doi.org/10.4236/eng.2013.55058

[3] Capata, R. (2015) Experimental Tests of the Operating Conditions of a Micro Gas Turbine Device. Energy and Power Engineering, 9, 326-335.

[4] (2016) Website: JETCAT Manufacturing. http://www.jetcat.de/downloads/manualp60p200eng.pdf

[5] Capata, R. and Sciubba, E. (2009) The $\alpha$-Prototype of an Ultra-Micro-Gas Turbine at the University of Roma 1. Final Assembly and Tests. IMECE2009-12281. Proceedings of IMECE, Lake Buena Vista, 13-19 November 2009.

[6] Capata, R. and Sciubba, E. (2009) The Ultra-Micro Gas Turbine Generator Project at UDR1: Experimental Assessment of the Compressor Map and of the Regenerative Combustion Chamber Efficiency. Proceedings of 22nd International Conference on Efficiency, Cost, Optimization, Simulation and Environmental Impact of Energy Systems, Parana, 30 August-3 September 2009.

[7] Minotti, A. and Sciubba, E. (2010) LES Simulation of an Ultra-Micro Combustion Chamber Based on a 177 Reactions Mechanism. Proceedings of the ASME-2010 10 th Biennial Conference on Engineering Systems Design and Analysis, Istanbul, 12-14 July 2010. http://dx.doi.org/10.1115/esda2010-24170

[8] ISO International Organization for Standardization (1995) Guide to the Expression of Uncertainty in Measurement. 2nd Edition, Geneva.

[9] Kacker, R. and Jones, A. (2003) On Use of Bayesian Statistics to Make the Guide to the Expression of Uncertainty in Measurement Consistent. National Institute of Standards and Technology, Gaithersburg.

[10] http://chapon.arnaud.free.fr/documents/resources/stat/GUM.pdf

[11] Taylor, N.B. and Kuyatt, C.E. (1994) NIST Technical Note 1297. 1994 Edition, Guidelines for Evaluating and Expressing the Uncertainty of NIST Measurement Results.

[12] Juvva, S.D.K., Mariappan, S. and Kushari, A. (2015) Open Loop Active Control of Combustion Noise in Gas Turbine Combustor. ASME Gas Turbine India Conference, Hyderabad, 2-3 December 2015.

[13] Araneo, R., Rinaldi, A., Notargiacomo, A., Bini, F., Pea, M., Celozzi, S., Marinozzi, F. and Lovat, G. (2014) Design Concepts, Fabrication and Advanced Characterization Methods of Innovative Piezoelectric Sensors Based on ZnO Nanowires. Sensors, 14, 23539-23562. http://dx.doi.org/10.3390/s141223539

[14] Araneo, R., Rinaldi, A., Notargiacomo, A., Bini, F., Marinozzi, F., Pea, M., Lovat, G. and Celozzi, S. (2014) Effect of the Scaling of the Mechanical Properties on the Performances of ZnO Piezo-Semiconductive Nanowires. Nanoforum 2013, AIP Conference Proceedings, 1603, 14-22. http://dx.doi.org/10.1063/1.4883037

[15] Janus, M.C. and Richards, G.A. (1996) A Model for Premixed Combustion Oscillations. Technical Note DOE/METC-96/1026 (DE96004366). U.S. Department of Energy, Office of Fossil Energy. Morgantown Energy Technology Center. http://www.metc.doe.gov 


\section{Abbreviations and Acronyms}

C: compressor

CC: combustion chamber

ICE: internal combustion engine

$\mathrm{n}$ : rotational speed [rpm]

p: pressure [Psi/bar/atm]

UDR1: University of Roma 1 "Sapienza”

UGMT: ultra micro gas turbine

T: turbine

TIT: turbine inlet temperature [K]

TOT: turbine outlet temperature [K]

Submit or recommend next manuscript to SCIRP and we will provide best service for you:

Accepting pre-submission inquiries through Email, Facebook, LinkedIn, Twitter, etc. A wide selection of journals (inclusive of 9 subjects, more than 200 journals)

Providing 24-hour high-quality service

User-friendly online submission system

Fair and swift peer-review system

Efficient typesetting and proofreading procedure

Display of the result of downloads and visits, as well as the number of cited articles

Maximum dissemination of your research work

Submit your manuscript at: http://papersubmission.scirp.org/

Or contact eng@scirp.org 